\title{
The Utilization and Safety of Umeclidinium and Umeclidinium/Vilanterol in UK Primary Care: A Retrospective Cohort Study
}

This article was published in the following Dove Press journal: International Journal of Chronic Obstructive Pulmonary Disease

\author{
Gema Requena' \\ Daniel Dedman (1D $)^{2}$ \\ Jennifer K Quint $\mathbb{D}^{3}$ \\ Rebecca E Ghosh (ID) ${ }^{2}$ \\ Rachael Williams ${ }^{2}$ \\ Jeanne M Pimenta' \\ 'Respiratory Epidemiology, GSK, \\ Brentford, Middlesex, UK; ${ }^{2}$ Clinical \\ Practice Research Datalink, MHRA, \\ London, UK; ${ }^{3}$ National Heart and Lung \\ Institute, Imperial College London, \\ London, UK
}

Background: Umeclidinium bromide (UMEC) and umeclidinium/vilanterol (UMEC/VI) received European approval for maintenance treatment of patients with chronic obstructive pulmonary disease (COPD) in 2014. This study examined prescribing patterns, possible offlabel prescribing, potential safety-related outcomes and adherence of these medications in routine clinical practice post-approval.

Methods: This retrospective, multi-database, longitudinal observational study of new users of UMEC, UMEC/VI, or other long-acting bronchodilators (LABD) analyzed data from UK electronic health record databases (primary care cohort), linked to hospital data (linked cohort). Off-label prescribing, safety outcomes (cardiovascular, respiratory, and mortality), treatment patterns, and medication adherence were assessed.

Results: In the primary care cohort (new users of UMEC $n=3875$; UMEC/VI $n=2224$; other LABD $n=32,809$ ), two-thirds of UMEC users were prescribed concomitant inhaled corticosteroids/long-acting $\beta_{2}$-agonists. Possible off-label prescribing, defined as use in patients without COPD, was similar for UMEC (7.0\%) and UMEC/VI $(8.8 \%)$, but higher for new users of other LABD (18.0\%). There were 547 UMEC users and 512 UMEC/VI users in the linked cohort. In both cohorts, incidence rates (IRs) of cardiovascular outcomes were similar for UMEC and UMEC/VI users (myocardial infarction IR per 1000 person-years [95\% CIs]: UMEC 6.9 [4.4, 10.2]; UMEC/VI 6.8 [3.5, 11.9]). IRs of pneumonia and acute COPD exacerbations (AECOPD) were slightly higher among UMEC users compared with UMEC/VI users (AECOPD IR per 1000 person-years [95\% CIs]: UMEC 979 [931, 1030]; UMEC/VI 746 [687, 811]). Adherence (medication possession ratio $\geq 80 \%$ ) was $64 \%$ for UMEC and UMEC/VI.

Conclusion: Most new users of UMEC were receiving multiple-inhaler triple therapy. Offlabel prescribing was uncommon for new users of UMEC and UMEC/VI. Incidence of cardiovascular and respiratory outcomes was as expected for these drug classes. This study provides evidence that UMEC and UMEC/VI are being prescribed appropriately and their safety profile remains unchanged.

Keywords: chronic obstructive pulmonary disease, electronic medical records, long-acting $\beta_{2}$-agonist, long-acting muscarinic antagonist, umeclidinium, umeclidinium/vilanterol

\section{Plain Language Summary Why Was the Study Done?}

Umeclidinium bromide (UMEC) and umeclidinium/vilanterol (UMEC/VI) are inhaled longacting bronchodilator medications that relax the airways and improve breathing; they were
Correspondence: Gema Requena

Respiratory Epidemiology, GSK, 980

Great West Road, Brentford, Middlesex,

TW8 9GS, UK

Tel +442080 476893

Email gema.x.requena@gsk.com
International Journal of Chronic Obstructive Pulmonary Disease 2021:16 629-642

629

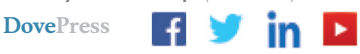


approved for the treatment of patients with chronic obstructive pulmonary disease (COPD) in 2014. Clinical trials demonstrated that UMEC and UMEC/VI improve patients' COPD and there were no major safety concerns. However, studies in routine care have yet to investigate if doctors are prescribing these treatments off-label (for use in a way not specified in the approval of the treatments), how often adverse medical events occur, and if patients are taking these treatments according to prescribed instructions (adherence).

\section{What Did the Researchers Do and Find?}

Information from UK electronic health record databases was analyzed. Possible off-label prescribing occurred infrequently for both UMEC and UMEC/VI. The rates of cardiovascular events were similar for patients taking UMEC or UMEC/VI; the rates of pneumonia and COPD exacerbations (flare-ups) were slightly higher for patients taking UMEC compared with UMEC/VI. The level of adherence to taking UMEC and UMEC/VI was similar.

\section{What Do These Results Mean?}

In the UK, UMEC and UMEC/VI are being prescribed appropriately for patients with COPD and their safety profile remains unchanged.

\section{Introduction}

The aims of pharmacological treatment in patients with chronic obstructive pulmonary disease (COPD) are to reduce symptom burden, prevent exacerbations and deterioration, reduce mortality, and improve exercise tolerance and health status. ${ }^{1}$ The Global Initiative for Chronic Obstructive Lung Disease (GOLD) recommends longacting bronchodilator (LABD) monotherapy (a longacting muscarinic antagonist [LAMA] or a long-acting $\beta_{2}$-agonist [LABA]) as initial maintenance therapy for most patients with COPD. ${ }^{1}$ In patients with severe symptoms or persistent exacerbations, treatment can be stepped up to dual (LAMA/LABA or inhaled corticosteroid [ICS]/LABA) or triple (ICS/LAMA/LABA) therapy. ${ }^{1}$ With the exception of tiotropium, neither LAMAs nor LAMA/LABA dual therapies are approved or recommended for maintenance treatment of patients with asthma. $^{2,3}$

Umeclidinium bromide (UMEC), a LAMA monotherapy, and umeclidinium/vilanterol (UMEC/VI), a LAMA/LABA dual therapy, received European approval for maintenance treatment of patients with COPD in 2014. ${ }^{4,5}$ The efficacy and safety of UMEC and UMEC/VI in COPD have been established in clinical trials, ${ }^{6-13}$ but further investigation of their utilization in the early post-approval period is needed to assess appropriate prescribing and confirm the safety of UMEC and UMEC/VI in routine clinical practice. To address this need, this study aimed first to quantify off-label prescribing among new users of UMEC/VI, UMEC, and other LABDs and to describe these patients in terms of clinical characteristics, disease severity, comorbidities, and previous and concomitant treatment. The second aim was to measure the incidence of potential safety-related outcomes among new users of these drug classes, such as major cardiovascular and cerebrovascular events, pneumonia, acute exacerbations of COPD (AECOPD), and mortality. Furthermore, the study aimed to describe adherence among new users of UMEC/VI or UMEC with $\geq 12$ months of follow-up.

\section{Materials and Methods}

\section{Study Design and Sources of Data}

This was a retrospective, multi-database, observational study of patients included in two UK electronic health record (EHR) databases: Clinical Practice Research Datalink GOLD (CPRD GOLD) and The Health Improvement Network (THIN). More details about these databases are presented in Supplementary materials. To avoid duplication, data from THIN were removed from practices that contributed to both databases. To facilitate the assessment of outcomes that were diagnosed and/or treated in a hospital inpatient setting and mortality, a subset of patients in CPRD GOLD was linked to pseudonymized Hospital Episode Statistics (HES) and Office of National Statistics (ONS) data. Patients were eligible for linkage if they were registered in English practices contributing to the linkage scheme, had a valid National Health Service (NHS) number, and had not dissented from data transfer to NHS Digital (the third-party provider of linkage).

The study population consisted of patients who were newly prescribed UMEC, UMEC/VI or another LABD in the UK between July 1, 2014 and June 30, 2016 (Figure 1). New use was defined as never previously having a prescription for the treatment. The index date was defined as the date of new use of UMEC/VI, UMEC or other LABD prescription within the inclusion period. Inclusion criteria and drugs included in "other LABD" are shown in Supplementary materials. A single patient could contribute to one or more qualifying index medication cohorts. Concomitant respiratory therapies at index were permitted and were defined as two or more continuous prescriptions 
Index date:

First prescription for UMEC/VI, UMEC, or other LABD

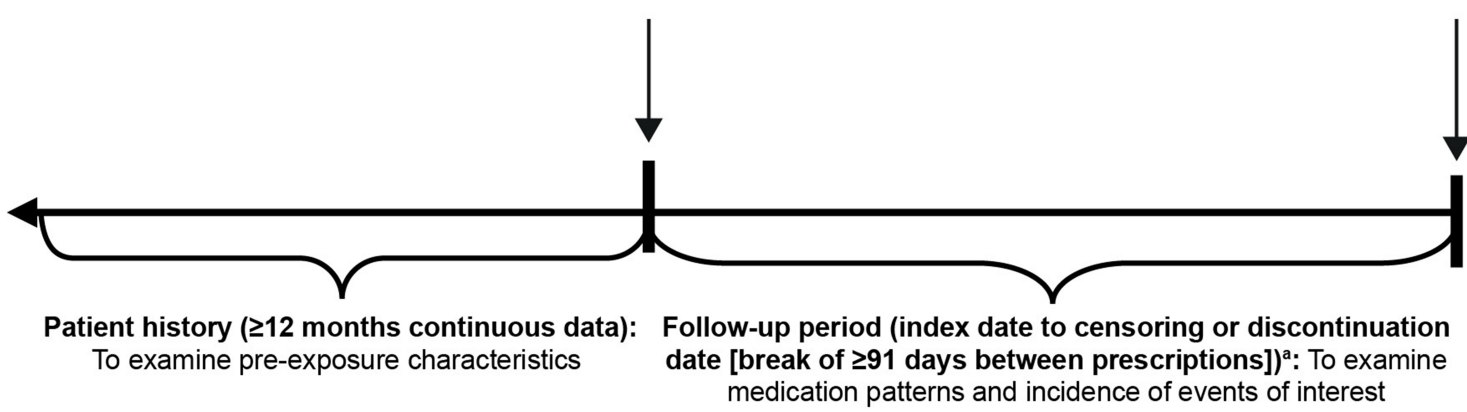

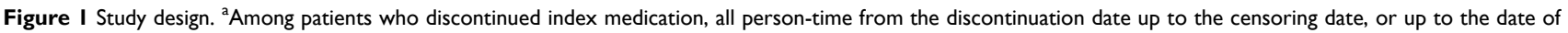
resumption of the index medication (if applicable), was classified as not currently exposed.

Abbreviations: GP, general practitioner; LABD, long-acting bronchodilator; UMEC, umeclidinium; UMEC/VI, umeclidinium/vilanterol.

that started up to and including 30 days after the index date and overlapped for $\geq 30$ days with the index treatment.

\section{Study Cohorts and Diagnosis Subgroups}

The main study cohort was the "primary care" cohort, which consisted of all eligible patients included from the CPRD GOLD and THIN EHRs. The primary and secondary care "linked cohort" consisted of patients from the CPRD GOLD who were eligible for linkage to HES and ONS data.

All patients were classified into diagnosis subgroups based on a recorded diagnosis of COPD (in patients $\geq 35$ years of age), asthma, or "other" (neither COPD nor asthma) at any time in the patient's history until the end of the study.

\section{Outcomes}

Off-label prescribing was defined as prescribing of UMEC, UMEC/VI or other LABD in patients without evidence of COPD. However, there were two exemptions to this to allow for acceptable prescribing use:

1. Patients in the other LAMA subgroup without evidence of COPD but with evidence of asthma who entered the study on or after September 13, 2014, with an index prescription for tiotropium $2.5 \mu \mathrm{g}$ AND a concurrent prescription for ICS/LABA. This was implemented to account for the authorization of tiotropium as an add-on therapy for the treatment of asthma in patients with exacerbations in September 2014. ${ }^{3}$

2. Patients in the other LABA subgroup without evidence of COPD but with evidence of asthma who
Censoring date: At death, leaving GP practice, the practice's last collection date or end of follow-up on June 30, 2017 entered the study with an index prescription for other LABA AND were receiving concomitant ICS at index date.

Potential safety outcomes (cardiovascular outcomes, respiratory outcomes, and mortality) related to these drug classes were identified from primary care records, and where applicable from linked hospitalization (HES) data. Primary care data, and links to death registration data (ONS) were used to ascertain deaths from all causes, and from cardiovascular causes.

Cardiovascular outcomes included:

1. Myocardial infarction (MI) or stroke (including transient ischemic attack) in all patients. Events occurring within 7 days were considered the same episode.

2. Congestive heart failure (CHF) among patients with no prior history.

Respiratory outcomes included:

1. Pneumonia. Events occurring within 28 days were considered the same episode.

2. AECOPD based on a validated algorithm that included diagnosis codes for AECOPD, information on lower respiratory tract infections and related symptoms, and prescriptions for antibiotics and/or oral corticosteroids around the same time. ${ }^{14,15}$ Events occurring within 14 days were considered the same episode. 
Mortality outcomes included:

1. Deaths from any cause identified in the primary care and in the linked cohort.

2. Cardiovascular deaths (only identified in the linked cohort using death registration data as causes of death are not recorded in primary care data).

New users of UMEC and UMEC/VI were classified into mutually exclusive treatment pattern groups based on prescription records (only the first change in treatment was considered). For patients who were taking a concomitant COPD maintenance therapy at index, four treatment patterns were defined for the 12-month follow-up period: continuous use of both treatments; discontinuation of index treatment; discontinuation of concomitant treatment; discontinuation of both treatments on the same day. For patients not taking a concomitant COPD maintenance therapy at index, six mutually exclusive treatment patterns were defined (Supplementary Figure 1).

Treatment adherence was assessed during the 12 months following the index prescription of UMEC or UMEC/VI in patients with at least 12 months' follow-up. Two complementary methods of calculating adherence were used: medication possession ratio (MPR), and proportion of days covered (PDC) (Supplementary materials), and adherence was defined as $\geq 80 \%$ for both measures.

\section{Data Analyses}

This was a descriptive study; treatment groups were not balanced and no formal statistical comparisons between groups were conducted. Analyses were performed using Stata (StataCorp; College Station, TX). Off-label prescribing was analyzed for all patients prescribed index treatment of UMEC, UMEC/VI, or other LABD in the primary care cohort. Safety outcomes were analyzed for new users of UMEC or UMEC/VI for the primary care and linked cohorts. The main safety analysis was during the exposure to the index medication ("on-treatment") and was stratified by concurrent ICS use. In addition, two sensitivity analyses were performed, one taking into account the whole follow-up time ("intention-to-treat"), which was also stratified by concurrent ICS use; and another, taking into account the time of exposure to concomitant COPD maintenance therapy.

Total number of events were analyzed for stroke, MI, and pneumonia; however, incidence rates (IRs) were only calculated for first events. CHF was only analyzed in patients without a history of CHF and only the first event was counted. First and all subsequent AECOPD episodes were considered in event rate calculations and event counts; IRs and 95\% confidence intervals (CI) were calculated using negative binomial regression to account for additional inter-individual variation in baseline risk. Adherence was analyzed for patients in the primary care cohort with $\geq 12$ months of follow-up. The mean and standard deviation (SD) MPR and PDC, and the proportion of adherent patients (defined as MPR or PDC $\geq 80 \%$ ), were calculated.

\section{Results}

\section{Patient Demographics and Clinical Characteristics}

In the primary care cohort, there were 3875 new users of UMEC, 2224 new users of UMEC/VI, and 32,809 new users of other LABDs. The mean (SD) follow-up time was 565.3 (268.6) days. The linked cohort comprised 547 new users of UMEC, 512 new users of UMEC/VI, and 10,590 new users of other LABD. The mean (SD) follow-up time was 493.3 (286.1) days.

In the primary care cohort, the three treatment groups had similar characteristics; however, a greater proportion of new users of other LABDs were under 35 years of age and had never smoked and a smaller proportion had pre-existing cardiovascular disease compared with new users of UMEC and UMEC/VI (Table 1). New users of UMEC had a higher rate of moderate COPD exacerbations in the year prior to index date than new users of UMEC/VI and other LABD (Table 1). The baseline demographics of the linked cohort (all from English practices) were similar to the total primary care cohort (of which, 45.9\% [17867/38908] were from English practices) (Supplementary Table 1).

In the 12 months prior to index date, a greater proportion of new users of UMEC received short-acting bronchodilators or a fixed-dose combination of ICS/LABA versus users of UMEC/VI and other LABD (Figure 2A). At index date, $68.3 \%(2648 / 3875)$ of new users of UMEC were prescribed concomitant maintenance treatment compared with $21.8 \%$ (485/2224) of UMEC/VI users. A high proportion of UMEC users were taking ICS/LABA medications (Figure 2B) and were therefore stepping up to multiple-inhaler triple therapy (MITT) or switching to UMEC from another LAMA. Among UMEC users, patients with and without concomitant treatment were similar in terms of age, sex, smoking status, and body mass index (BMI); however, patients prescribed concomitant medications had a higher incidence of moderate COPD exacerbations in the 12 months prior to 
Table I Demographic Characteristics and Comorbidities at Baseline in the Primary Care Cohort

\begin{tabular}{|c|c|c|c|}
\hline Characteristics & UMEC $(n=3875)$ & UMEC/VI $(n=2224)$ & Other LABD $(n=32,809)$ \\
\hline Age at index, mean years (SD) & $68.8(10.8)$ & $69.0(10.7)$ & $65.7(14.9)$ \\
\hline \multicolumn{4}{|l|}{ Age category, years, n (\%) } \\
\hline$<18$ years & $0(0)$ & $0(0)$ & $609(1.9)$ \\
\hline $18-34$ years & $16(0.4)$ & $6(0.3)$ & $600(1.8)$ \\
\hline $35-64$ years & $1237(31.9)$ & $686(30.8)$ & II,863 (36.2) \\
\hline$\geq 65$ years & $2622(67.7)$ & $1532(68.9)$ & $19,737(60.2)$ \\
\hline Female, n (\%) & $1984(5 \mid .2)$ & $1055(47.4)$ & $16,723(5 \mid .0)$ \\
\hline \multicolumn{4}{|l|}{ Smoking status, n (\%) } \\
\hline Current smoker & $1656(42.7)$ & $883(39.7)$ & 13,107 (39.9) \\
\hline Ex-smoker & $1886(48.7)$ & $1152(51.8)$ & $14,435(44.0)$ \\
\hline Never smoker & $332(8.6)$ & $188(8.5)$ & 4947 (I5.I) \\
\hline Missing ${ }^{\mathrm{a}}$ & I (0) & I (0) & $320(1.0)$ \\
\hline BMI mean $\mathrm{kg} / \mathrm{m}^{2}(\mathrm{SD})$ & $27.9(6.5)$ & $28.4(6.4)$ & $28.0(6.7)$ \\
\hline Underweight $\left(<18.5 \mathrm{~kg} / \mathrm{m}^{2}\right), \mathrm{n}(\%)$ & $189(4.9)$ & $82(3.7)$ & $1367(4.2)$ \\
\hline Normal $\left(18.5-24.9 \mathrm{~kg} / \mathrm{m}^{2}\right), \mathrm{n}(\%)$ & $1162(30.0)$ & $615(27.7)$ & $9680(29.5)$ \\
\hline Overweight $\left(25.0-29.9 \mathrm{~kg} / \mathrm{m}^{2}\right), \mathrm{n}(\%)$ & $1228(3 \mid .7)$ & 732 (32.9) & $9987(30.4)$ \\
\hline Obese $\left(\geq 30 \mathrm{~kg} / \mathrm{m}^{2}\right), \mathrm{n}(\%)$ & $1244(32.1)$ & $770(34.6)$ & $10,326(31.5)$ \\
\hline Missing ${ }^{\mathrm{a}}, \mathrm{n}(\%)$ & $52(1.3)$ & $25(1.1)$ & $1449(4.4)$ \\
\hline \multicolumn{4}{|l|}{ Comorbidities $^{\mathrm{b}}, \mathrm{n}(\%)$} \\
\hline Cardiovascular disease & $2510(64.8)$ & $1453(65.3)$ & $|9,7| \mid(60.1)$ \\
\hline Prescription for a beta-blocker & $707(18.2)$ & $485(21.8)$ & $6391(19.5)$ \\
\hline Pneumonia & $284(7.3)$ & $160(7.2)$ & $2312(7.0)$ \\
\hline Gastroesophageal disease & $890(23.0)$ & $525(23.6)$ & $7440(22.7)$ \\
\hline Diabetes & $753(19.4)$ & $410(18.4)$ & $5863(17.9)$ \\
\hline Kidney disease & $826(21.3)$ & $438(19.7)$ & $5883(17.9)$ \\
\hline Cancer & $564(14.6)$ & $313(14.1)$ & $4287(13.1)$ \\
\hline \multicolumn{4}{|c|}{ "Moderate" COPD exacerbations in the previous year ${ }^{c}$} \\
\hline Rate per 1000 person-years $(95 \% \mathrm{Cl})$ & $1091(1058,1124)$ & $769(734,807)$ & $830(820,840)$ \\
\hline 0 events, $n(\%)$ & $1826(47.1)$ & $1257(56.5)$ & $17,629(53.7)$ \\
\hline I event, n (\%) & $984(25.4)$ & $563(25.3)$ & $8535(26.0)$ \\
\hline$\geq 2$ events, $n(\%)$ & $1065(27.5)$ & $404(18.2)$ & $6645(20.3)$ \\
\hline Dyspnea, mean (SD) & $2.8(1.0)$ & $2.7(0.9)$ & $2.6(1.0)$ \\
\hline MRC grade I, n (\%) & $196(6.5)$ & $100(5.9)$ & $1643(9.2)$ \\
\hline MRC grade 2, n (\%) & $1070(35.5)$ & $680(40.4)$ & 7091 (39.8) \\
\hline MRC grade $3, \mathrm{n}(\%)$ & $1018(33.7)$ & $585(34.8)$ & $5586(31.4)$ \\
\hline MRC grade $4, n(\%)$ & $629(20.8)$ & $278(16.5)$ & $2935(16.5)$ \\
\hline MRC grade 5, n (\%) & $105(3.5)$ & $40(2.4)$ & $545(3.1)$ \\
\hline Missing ${ }^{\mathrm{a}}, \mathrm{n}(\%)$ & $1186(30.6)$ & $599(26.9)$ & $12,200(37.2)$ \\
\hline FEV , \% predicted, mean (SD) & $58.1(19.2)$ & $60.0(19.0)$ & $59.8(19.4)$ \\
\hline Mild, Grade I ( $\geq 80 \%)$, n (\%) & $329(12.2)$ & $226(13.9)$ & $2882(14.0)$ \\
\hline Moderate, Grade 2 ( $\geq 50 \%$ to $<80 \%), n(\%)$ & $1427(53.1)$ & $915(56.3)$ & $11,312(54.9)$ \\
\hline Severe, Grade 3 ( $\geq 30 \%$ to $<50 \%)$, n (\%) & $768(28.6)$ & $40 \mathrm{I}(24.7)$ & $5266(25.6)$ \\
\hline Very severe, Grade 4 (<30\%), n (\%) & $165(6.1)$ & $83(5.1)$ & $1149(5.6)$ \\
\hline Missing ${ }^{\mathrm{a}}, \mathrm{n}(\%)$ & $1186(30.6)$ & $599(26.9)$ & $12,200(37.2)$ \\
\hline
\end{tabular}

(Continued) 
Table I (Continued).

\begin{tabular}{|l|c|c|c|}
\hline Characteristics & UMEC $(\mathbf{n = 3 8 7 5 )}$ & UMEC/VI $(\mathbf{n}=2224)$ & Other LABD (n=32,809) \\
\hline FEV /FVC ratio, mean (SD) & $58.9(15.9)$ & $60.4(14.1)$ & $62.1(15.6)$ \\
$<70 \%, n(\%)$ & $1752(79.1)$ & $1130(77.8)$ & $12,866(72.1)$ \\
$\geq 70 \%, n(\%)$ & $464(20.9)$ & $323(22.2)$ & $4975(27.9)$ \\
Missing, $n$ (\%) & $1659(42.8)$ & $77 \mid(34.7)$ & $14,968(45.6)$ \\
\hline
\end{tabular}

Notes: ${ }^{\text {P}}$ Percentages were calculated separately for those with missing and without missing data; ${ }^{\mathrm{b}}$ patients who had ever had a diagnosis or who had a prescription for betablockers in the previous 12 months; 'according to primary care data.

Abbreviations: BMI, body mass index; $\mathrm{Cl}$, confidence interval; COPD, chronic obstructive pulmonary disease; FEV vital capacity; LABD, long-acting bronchodilator; MRC, Medical Research Council; SD, standard deviation; UMEC, umeclidinium; UMEC/VI, umeclidinium/vilanterol.

index date (1336 per 1000 person-years [95\% CI: 1293, research council [MRC] grade 4 or 5) and worse lung 1381] vs 560 per 1000 person-years [95\% CI: 520, 603]), function $(41.2 \%$ vs $19.9 \%$ with forced expiratory volume had more severe dyspnea $\left(29.2 \%\right.$ vs $12.8 \%$ with medical in 1 second $\left[\mathrm{FEV}_{1}\right] \%$ predicted $\left.<50 \%\right)$. New users of
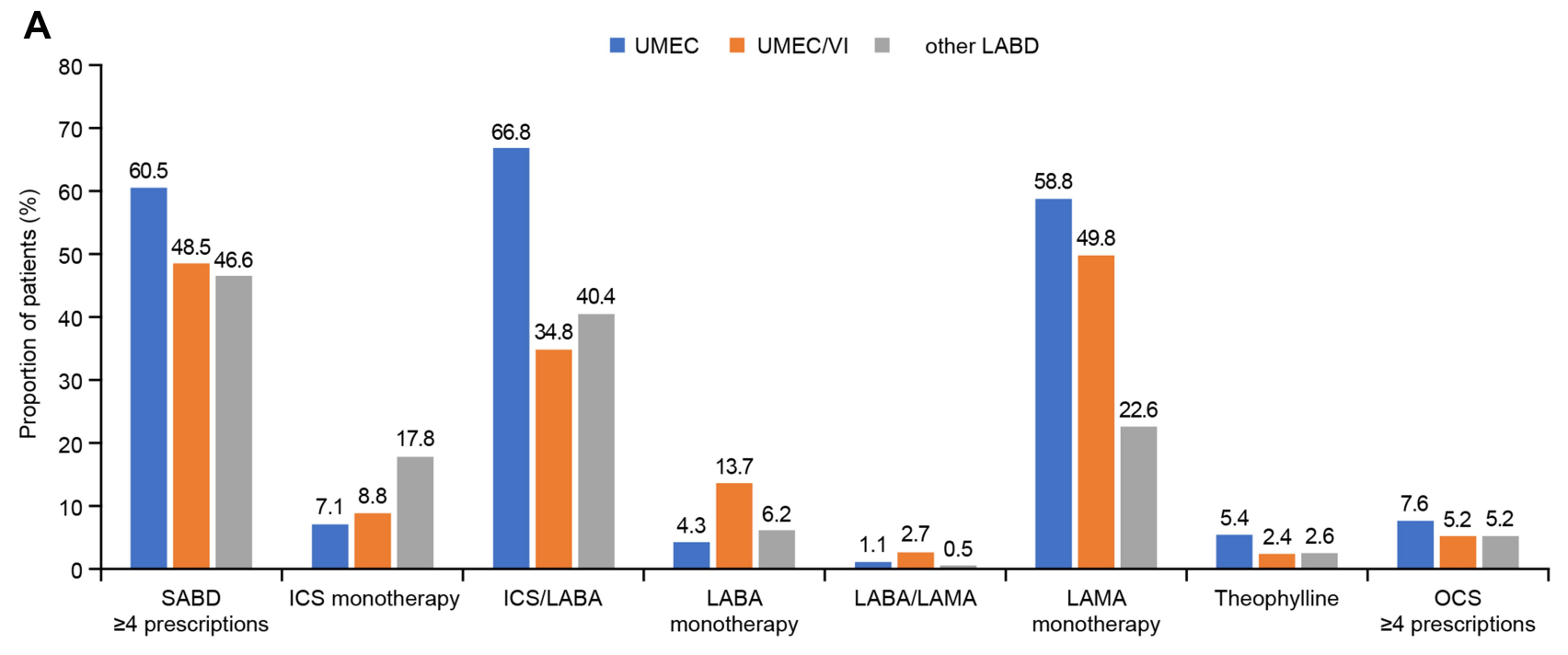

B

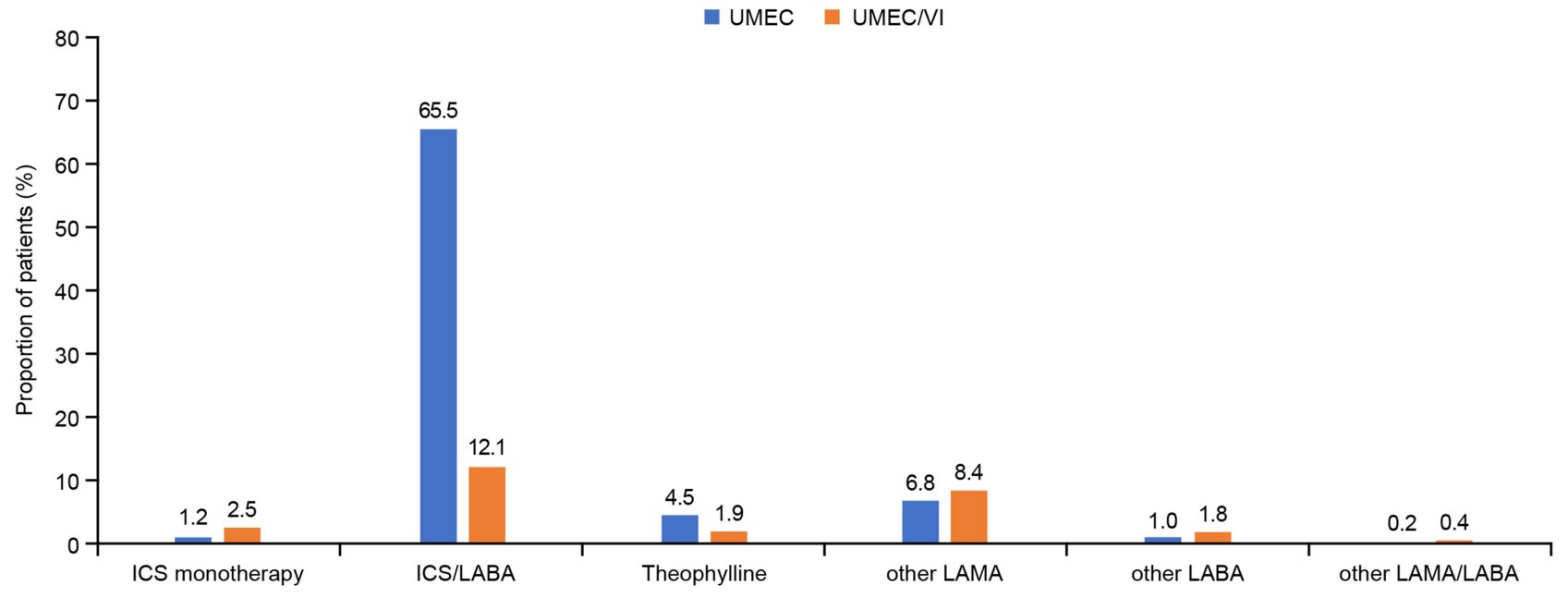

Figure 2 Previous (A) and concomitant (B) use of inhaled COPD maintenance therapy at index in the primary care cohort.

Abbreviations: ICS, inhaled corticosteroids; LABA, long-acting $\beta_{2}$-agonist; LABD, long-acting bronchodilator; LAMA, long-acting muscarinic antagonist; OCS, oral corticosteroids; SABD, short-acting bronchodilator; UMEC, umeclidinium; UMEC/VI, umeclidinium/vilanterol. 
UMEC/VI receiving versus not receiving concomitant medications also had a higher incidence of moderate COPD exacerbations in the 12 months prior to index date (1252 per 1000 person-years [95\% CI: 1156, 1355] vs 635 per 1000 person-years [95\% CI: 598, 673]), had more severe dyspnea $(27.2 \%$ vs $16.5 \%$ with MRC grade 4 or 5$)$ and worse lung function $\left(40.5 \%\right.$ vs $26.6 \%$ with $\mathrm{FEV}_{1} \%$ predicted $<50 \%$ ).

\section{Possible Off-Label Prescribing of UMEC, UMEC/VI, and Other LABD}

Possible off-label use of UMEC and UMEC/VI was low as most patients had a diagnosis of COPD (Table 2). Overall, $7.0 \%$ of new users of UMEC and $8.8 \%$ of new users of UMEC/VI in the primary care cohort were considered to have received possible off-label treatment compared with $18.0 \%$ of other LABD users (Table 2). There were $130(3.4 \%)$ new users of UMEC and 69 (3.1\%) new users of UMEC/VI with an asthma diagnosis, of whom 34 ( $0.9 \%$ of all UMEC patients) and $39(1.8 \%$ of all UMEC/VI users), respectively, were not taking concomitant ICS at the index date, suggesting possible off-label use. For both UMEC and UMEC/VI users, concomitant ICS use was lower in the subgroup of patients without a diagnosis of COPD or asthma compared with patients with either diagnosis.

Analysis of patient characteristics by diagnosis shows that for UMEC and UMEC/VI users, patients with COPD tended to be older, were more likely to be male, and tended to have poorer lung function than those with an asthma diagnosis (Supplementary Table 2).

\section{Potential Safety-Related Outcomes}

In the main on-treatment safety analysis, the IR of cardiovascular outcomes (MI, stroke, and newly diagnosed CHF) was similar among UMEC and UMEC/VI users in the primary care (Table 3 ) and linked (Table 4) cohorts. Secondary analyses of all follow-up (ie, including any time between discontinuation of the index medication and censoring or restarting of index medication) showed the IR of cardiovascular outcomes was similar for both UMEC and UMEC/VI users (Supplementary Table 3). Furthermore, among new users of UMEC and UMEC/VI, analyses in patients prescribed versus not prescribed concomitant COPD maintenance therapy showed similar IRs of cardiovascular outcomes (Supplementary Table 3).

In the main on-treatment analysis, IRs of pneumonia and moderate AECOPD were higher among UMEC versus UMEC/VI users in the primary care cohort and were higher among patients treated with versus without ICS at the index date and in patients with versus without concurrent maintenance treatment (Table 3 and Supplementary Table 4). In both index treatment groups, IRs of pneumonia and AECOPD were substantially higher in the linked cohort than in the primary care cohort; however, the definitions of these outcomes were different for the two cohorts (Tables 3 and 4). AECOPD were much more frequent than pneumonia events in both cohorts; however, the IRs for these outcomes were calculated differently, with only first events included for pneumonia. IRs of respiratory outcomes during all available follow-up in the primary care cohort were similar to the on-treatment analysis (Table 3 and Supplementary Table 3).

Table 2 Diagnosis and Possible Off-Label Prescribing in the Primary Care Cohort $(\mathrm{N}=34,5 \mathrm{I})$

\begin{tabular}{|l|c|c|c|c|c|}
\hline Index Therapy & $\begin{array}{c}\text { All New } \\
\text { Users }\end{array}$ & COPD & Asthma & Other (Not COPD or & $\begin{array}{c}\text { Possible Off-Label } \\
\text { Psthma) }\end{array}$ \\
\hline All, $\mathrm{n}(\%)$ & 38,908 & $31,000(79.7)$ & $4876(12.5)$ & $3032(7.8)$ & $6385(16.4)^{\mathrm{b}}$ \\
UMEC, n (\%) & 3875 & $3604(93.0)$ & $130(3.4)$ & $141(3.6)$ & $271(7.0)^{\mathrm{c}}$ \\
UMEC/VI, n (\%) & 2224 & $2029(91.2)$ & $69(3.1)$ & $126(5.7)$ & $195(8.8)^{\mathrm{c}}$ \\
Other LABD, n (\%) & 32,809 & $25,367(77.3)$ & $4677(14.3)$ & $2765(8.4)$ & $5919(18.0)^{\mathrm{b}}$ \\
Other LAMA, n (\%) & 24,125 & $19,655(81.5)$ & $2327(9.6)$ & $2143(8.9)$ & $3980(16.5)^{\mathrm{b}}$ \\
Other LABA, n (\%) & 6218 & $3458(55.6)$ & $2278(36.6)$ & $482(7.8)$ & $1727(27.8)^{\mathrm{b}}$ \\
Other LABA/LAMA, n (\%) & 2466 & $2254(91.4)$ & $72(2.9)$ & $140(5.7)$ & $212(8.6)^{\mathrm{c}}$ \\
\hline
\end{tabular}

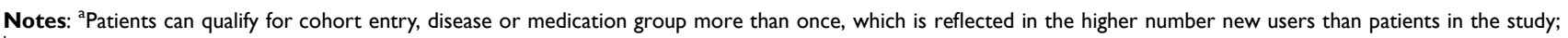
b defined as all patients without a diagnosis code of COPD at any time, with the exception of a) patients with a diagnosis of asthma prescribed index tiotropium $2.5 \mu g$, (other LAMA), if they entered the study on or after September 13,2014, with a concurrent prescription for ICS/LABA; b) patients with a diagnosis of asthma prescribed an index other LABA and were receiving concomitant ICS at index date; 'defined as patients without a diagnosis of COPD only.

Abbreviations: COPD, chronic obstructive pulmonary disease; ICS, inhaled corticosteroid; LABA, long-acting $\beta_{2}$-agonist; LABD, long-acting bronchodilator; LAMA, longacting muscarinic antagonist; UMEC, umeclidinium; UMEC/VI, umeclidinium/vilanterol. 
Table 3 On-Treatment Cardiovascular, Respiratory, and All-Cause Mortality Outcomes in New Users of UMEC/VI and UMEC in the Primary Care Cohort

\begin{tabular}{|c|c|c|c|c|}
\hline \multirow[t]{2}{*}{ Outcome } & \multicolumn{2}{|c|}{ UMEC (n=3875; 3508.7 Person-Years $\left.{ }^{a}\right)$} & \multicolumn{2}{|c|}{ UMEC/VI (n=2224; I 768.3 Person-Years $\left.{ }^{\mathrm{a}}\right)$} \\
\hline & $\begin{array}{c}\text { Total } \\
\text { Events }^{\mathbf{b}}, \mathbf{n}\end{array}$ & $\begin{array}{l}\text { IR per I000 Patient-Years } \\
\qquad(95 \% \mathrm{Cl})^{\mathrm{c}, \mathrm{d}}\end{array}$ & $\begin{array}{c}\text { Total } \\
\text { Events }^{\mathbf{b}}, \mathbf{n}\end{array}$ & $\begin{array}{c}\text { IR per } 1000 \text { Patient-Years } \\
(95 \% \mathrm{CI})^{\text {c.d }}\end{array}$ \\
\hline \multicolumn{5}{|l|}{ MI } \\
\hline All patients & 27 & $6.9(4.4,10.2)$ & 13 & $6.8(3.5,11.9)$ \\
\hline With ICS use at index date & 19 & $6.7(3.9,10.7)$ & 0 & $0.0(0.0,21.6)$ \\
\hline No ICS use at index date & 8 & $7.4(3.0,15.3)$ & 13 & $7.5(3.9,13.2)$ \\
\hline \multicolumn{5}{|l|}{ Stroke } \\
\hline All patients & $|7|$ & $30.9(25.3,37.4)$ & 84 & $30.5(22.8 .39 .8)$ \\
\hline With ICS use at index date & 113 & $26.7(20.7,33.9)$ & 7 & $23.7(6.5,60.7)$ \\
\hline No ICS use at index date & 58 & $42.3(30.1,57.9)$ & 77 & $3 \mid .2(23 .|, 4| .2)$ \\
\hline \multicolumn{5}{|l|}{ Newly diagnosed $\mathrm{CHF}^{\mathrm{e}}$} \\
\hline All patients & 48 & $14.8(10.9,19.6)$ & 18 & II.0 (6.5, I7.4) \\
\hline With ICS use at index date & 35 & $14.9(10.4,20.7)$ & 0 & $0.0(0.0,23.8)$ \\
\hline No ICS use at index date & 13 & I $4.5(7.7,24.8)$ & 18 & $12.2(7.2,19.2)$ \\
\hline \multicolumn{5}{|l|}{ Pneumonia (primary care) } \\
\hline All patients & 25 & $6.9(4.4,10.2)$ & 6 & $3.4(1.2,7.4)$ \\
\hline With ICS use at index date & $21-24$ & Not calculated & $2-5$ & Not calculated \\
\hline No ICS use at index date & $\mathrm{I}-4$ & Not calculated & $\mathrm{I}-4$ & Not calculated \\
\hline \multicolumn{5}{|l|}{ Moderate AECOPD ${ }^{d}$} \\
\hline All patients & 3409 & 979 (931, 1030) & 1275 & $746(687,8 \mathrm{II})$ \\
\hline With ICS use at index date & 2919 & II $157(1098,1220)$ & 231 & 1335 (1097, I626) \\
\hline No ICS use at index date & 490 & $534(467,610)$ & 1044 & $675(617,738)$ \\
\hline \multicolumn{5}{|l|}{ Death (all causes) } \\
\hline All patients & 105 & $29.9(24.5,36.2)$ & 62 & $35.1(26.9,44.9)$ \\
\hline With ICS use at index date & 77 & $30.1(23.7,37.6)$ & 5 & $29.3(9.5,68.3)$ \\
\hline No ICS use at index date & 28 & $29.6(19.7,42.8)$ & 57 & $35.7(27.0,46.2)$ \\
\hline
\end{tabular}

Notes: ${ }^{a}$ Follow-up time for the full cohort; ${ }^{b}$ includes first and subsequent events. Ranges are shown where $<5$ events were reported; ${ }^{c}$ incidence based on first event only; ${ }^{d}$ for AECOPD, all events were included; ${ }^{e}$ patients with prior history of $\mathrm{CHF}$ were excluded.

Abbreviations: AECOPD, acute exacerbations of COPD; CHF, congestive heart failure; CI, confidence interval; COPD, chronic obstructive pulmonary disease; ICS, inhaled corticosteroid; IR, incidence rate; MI, myocardial infarction; UMEC, umeclidinium; UMEC/VI, umeclidinium/vilanterol.

In the main, on-treatment analysis, $105(2.7 \%)$ new users of UMEC and $62(2.8 \%)$ new users of UMEC/VI died; mortality was slightly higher in the linked cohort (UMEC, 18 [3.3\%] patients; UMEC/VI, 19 [3.7\%] patients) versus the primary care cohort (Tables 3 and 4). In the on-treatment analysis of both cohorts, mortality was higher among new users of UMEC/VI not taking concomitant ICS at index compared with those who were taking ICS (Tables 3 and 4). All-cause mortality during all available follow-up was higher than observed during the ontreatment analysis (Supplementary Table 3). All-cause mortality was similar among patients who were or were not receiving other respiratory therapies concurrently (Supplementary Table 4).

\section{Treatment Patterns}

In the primary care cohort, 32.3\% (1047/3240) of new users of UMEC with $\geq 12$ months of follow-up were not receiving concomitant COPD maintenance therapy at the index date, compared with $81.1 \%$ (1478/1822) of new users of UMEC/VI (Table 5). Among patients receiving UMEC and no concomitant COPD maintenance therapy, $35.4 \%$ (371/1047) continued to receive UMEC for $\geq 12$ months. Over half of patients who discontinued UMEC 
Table 4 On-Treatment Cardiovascular, Respiratory, and All-Cause Mortality Outcomes in New Users of UMEC/VI and UMEC in the Linked Cohort

\begin{tabular}{|c|c|c|c|c|}
\hline \multirow[t]{2}{*}{ Outcome } & \multicolumn{2}{|c|}{ UMEC ( $n=547 ; 374.7$ Person-Years) } & \multicolumn{2}{|c|}{ UMEC/VI (n=5 I 2; 365.6 Person-Years) } \\
\hline & $\begin{array}{c}\text { Total } \\
\text { Events }^{\mathbf{a}}, \mathbf{n}\end{array}$ & $\begin{array}{l}\text { IR per I000 Patient-Years } \\
(95 \% \mathrm{Cl})^{\mathrm{b}, \mathrm{c}}\end{array}$ & $\begin{array}{c}\text { Total } \\
\text { Events }^{\mathbf{a}}, \mathbf{n}\end{array}$ & $\begin{array}{c}\text { IR per } 1000 \text { Patient-Years } \\
(95 \% \mathrm{CI})^{\mathrm{b}, \mathrm{c}}\end{array}$ \\
\hline \multicolumn{5}{|l|}{ MI } \\
\hline $\begin{array}{l}\text { All patients } \\
\text { With ICS use at index date } \\
\text { No ICS use at index date }\end{array}$ & $\begin{array}{c}5 \\
1-4 \\
1-4\end{array}$ & $\begin{array}{l}8.0(1.7,23.4) \\
\text { Not calculated } \\
\text { Not calculated }\end{array}$ & $\begin{array}{c}I-4 \\
0 \\
I-4\end{array}$ & $\begin{array}{l}\text { Not calculated } \\
\text { Not calculated } \\
\text { Not calculated }\end{array}$ \\
\hline \multicolumn{5}{|l|}{ Stroke } \\
\hline $\begin{array}{l}\text { All patients } \\
\text { With ICS use at index date } \\
\text { No ICS use at index date }\end{array}$ & $\begin{array}{l}19 \\
14 \\
5\end{array}$ & $\begin{array}{c}35.4(18.9,60.6) \\
31.1(13.4,61.4) \\
45.5(14.8,106.3)\end{array}$ & $\begin{array}{c}13 \\
1-4 \\
9-12\end{array}$ & $\begin{array}{l}\text { I6.5 }(6.1,36.0) \\
\text { Not calculated } \\
\text { Not calculated }\end{array}$ \\
\hline \multicolumn{5}{|l|}{ Newly diagnosed $\mathrm{CHF}^{\mathrm{d}}$} \\
\hline $\begin{array}{l}\text { All patients } \\
\text { With ICS use at index date } \\
\text { No ICS use at index date }\end{array}$ & $\begin{array}{l}5 \\
5 \\
0\end{array}$ & $\begin{array}{c}14.6(4.7,34.0) \\
21.0(6.8,49.0) \\
0.0(0.0,35.2)\end{array}$ & $\begin{array}{c}7 \\
1-4 \\
3-6\end{array}$ & $\begin{array}{l}20.5(8.3,42.3) \\
\text { Not calculated } \\
\text { Not calculated }\end{array}$ \\
\hline \multicolumn{5}{|c|}{ Pneumonia (primary and secondary care) } \\
\hline $\begin{array}{l}\text { All patients } \\
\text { With ICS use at index date } \\
\text { No ICS use at index date }\end{array}$ & $\begin{array}{c}25 \\
2 I-24 \\
I-4\end{array}$ & $\begin{array}{l}66.0(42.3,98.2) \\
\text { Not calculated } \\
\text { Not calculated }\end{array}$ & $\begin{array}{c}18 \\
1-4 \\
14-17\end{array}$ & $\begin{array}{l}47.3(27.5,75.7) \\
\text { Not calculated } \\
\text { Not calculated }\end{array}$ \\
\hline \multicolumn{5}{|c|}{ Moderate and severe AECOPD } \\
\hline $\begin{array}{l}\text { All patients } \\
\text { With ICS use at index date } \\
\text { No ICS use at index date }\end{array}$ & $\begin{array}{l}554 \\
437 \\
117\end{array}$ & $\begin{array}{l}1484(1326,166 \mid) \\
1658(147|,| 869) \\
1091(830,1434)\end{array}$ & $\begin{array}{l}421 \\
103 \\
318\end{array}$ & $\begin{array}{l}1168(1013,1345) \\
1931(1426,2616) \\
1027(880,1200)\end{array}$ \\
\hline \multicolumn{5}{|l|}{ Death (all causes) } \\
\hline $\begin{array}{l}\text { All patients } \\
\text { With ICS use at index date } \\
\text { No ICS use at index date }\end{array}$ & $\begin{array}{l}18 \\
12 \\
6\end{array}$ & $\begin{array}{c}48.0(28.5,75.9) \\
45.6(23.6,79.7) \\
53.8(19.7,117.0)\end{array}$ & $\begin{array}{c}19 \\
1-4 \\
15-18\end{array}$ & $\begin{array}{l}52.0(31.3,81.2) \\
\text { Not calculated } \\
\text { Not calculated }\end{array}$ \\
\hline \multicolumn{5}{|l|}{ Cardiovascular deaths } \\
\hline $\begin{array}{l}\text { All patients } \\
\text { With ICS use at index date } \\
\text { No ICS use at index date }\end{array}$ & $\begin{array}{l}1-4 \\
1-3 \\
1-3\end{array}$ & $\begin{array}{l}\text { Not calculated } \\
\text { Not calculated } \\
\text { Not calculated }\end{array}$ & $\begin{array}{l}6 \\
0 \\
6\end{array}$ & $\begin{array}{l}16.4(6.0,35.7) \\
0.0(0.0,71.8) \\
19.1(7.0,41.6)\end{array}$ \\
\hline
\end{tabular}

Notes: ${ }^{a}$ Includes first and subsequent events. Ranges are shown where $<5$ events were reported; ${ }^{b}$ incidence based on first event only; ${ }^{c}$ for AECOPD, all events were included; 'patients with prior history of CHF were excluded.

Abbreviations: AECOPD, acute exacerbations of COPD; $\mathrm{CHF}$, congestive heart failure; $\mathrm{Cl}$, confidence interval; COPD, chronic obstructive pulmonary disease; ICS, inhaled corticosteroid; IR, incidence rate; MI, myocardial infarction; UMEC, umeclidinium; UMEC/VI, umeclidinium/vilanterol.

resumed use after a hiatus of $\geq 90$ days. Among patients receiving UMEC and concomitant maintenance therapy, $67.5 \%(1480 / 2193)$ of patients continued to receive UMEC for $\geq 12$ months.

Among patients receiving UMEC/VI and no concomitant COPD maintenance therapy, $44.3 \%$ (807/1478) continued to receive UMEC/VI for $\geq 12$ months of follow-up. Among
UMEC/VI users receiving concomitant therapy, 49.4\% (170/ 344) of patients received UMEC/VI for $\geq 12$ months.

\section{Adherence}

Overall, 63.8\% (1734/2716) of UMEC users and 64.3\% (921/1432) of UMEC/VI users were adherent to index therapy based on having an MPR $\geq 80 \%$, whereas $41.1 \%$ (1332/ 
Table 5 Treatment Patterns ${ }^{\mathrm{a}}$ in the 12 Months Following Initiation of UMEC and UMEC/VI in the Primary Care Cohort

\begin{tabular}{|c|c|c|c|c|}
\hline \multirow[t]{2}{*}{ Treatment Pattern } & \multicolumn{2}{|c|}{ UMEC $(n=3240)$} & \multicolumn{2}{|c|}{ UMEC/VI $(n=1822)$} \\
\hline & $\mathrm{n},(\%)$ & $\begin{array}{c}\text { Days to First Change, } \\
\text { Mean (SD) }\end{array}$ & n, (\%) & $\begin{array}{c}\text { Days to First Change, } \\
\text { Mean (SD) }\end{array}$ \\
\hline \multicolumn{5}{|c|}{ No concomitant COPD maintenance therapy at index date } \\
\hline All patients & $1047(32.3)$ & & $1478(8 \mid .1)$ & \\
\hline Continuous user & $371(35.4)$ & $\mathrm{n} / \mathrm{a}$ & $655(44.3)$ & $\mathrm{n} / \mathrm{a}$ \\
\hline Augmenter & $32(3.1)$ & II $0.7(65.6)$ & $32(2.2)$ & II $8.2(72.0)$ \\
\hline Immediate switcher & $114(10.9)$ & $96.2(66.7)$ & $249(16.8)$ & I $20.7(88.9)$ \\
\hline Discontinuer & $530(50.6)$ & $106.5(98.5)$ & $542(36.7)$ & III.3 (95.9) \\
\hline True discontinuer & $216(40.8)$ & $96.2(98.2)$ & $177(32.7)$ & $84.4(89.7)$ \\
\hline Discontinuer with drug hiatus & $279(52.6)$ & $121.3(100.7)$ & $359(66.2)$ & $125.5(96.5)$ \\
\hline Discontinuer with latent switch & $35(6.6)$ & $53.1(41.0)$ & $6(1.1)$ & $55.8(31.5)$ \\
\hline \multicolumn{5}{|c|}{ With concomitant COPD maintenance therapy at index date } \\
\hline All patients & $2193(67.7)$ & & $344(18.9)$ & \\
\hline Continuous use of both drugs & $1116(50.9)$ & $\mathrm{n} / \mathrm{a}$ & $22(6.4)$ & $\mathrm{n} / \mathrm{a}$ \\
\hline Discontinuation of index drug only & $553(25.2)$ & $143.2(105.9)$ & $115(33.4)$ & $87.3(81.8)$ \\
\hline Discontinuation of concomitant drug only & $364(16.6)$ & II $4.7(99.4)$ & $148(43.0)$ & $68.4(70.4)$ \\
\hline Discontinuation of both drugs & I $60(7.3)$ & I25.4 (97.8) & $59(17.2)$ & $87.3(69.6)$ \\
\hline
\end{tabular}

Note: ${ }^{a}$ As defined in Supplementary Figure I.

Abbreviations: COPD, chronic obstructive pulmonary disease; SD, standard deviation; UMEC, umeclidinium; UMEC/VI, umeclidinium/vilanterol.

3240) of UMEC users and 32.9\% (59/1822) of UMEC/VI users were classified as adherent according to having a $\mathrm{PDC} \geq 80 \%$.

\section{Discussion}

This retrospective study combined patients from two primary care databases to identify and characterize new users of UMEC, UMEC/VI, and other LABD. Around twothirds of new users of UMEC were already receiving treatment with ICS/LABA and were therefore either stepping up to MITT or were already receiving triple therapy but switching to UMEC from a different LAMA. Prior to initiation of index treatment, new users of UMEC had more severe disease than new users of UMEC/VI or other LABDs, with a higher incidence of COPD exacerbations, more severe dyspnea and airflow limitation, which is consistent with the large proportion of patients receiving UMEC as a component of triple therapy. These characteristics of UMEC users appear to align with the GOLD report, which recommends triple therapy in patients with severe COPD and a risk of exacerbations. ${ }^{1}$

Few patients without a diagnosis of COPD were prescribed UMEC/VI or UMEC, suggesting that most general practitioners (GPs) are aware of the licensed indications for these treatments. A small proportion of new users of
UMEC or UMEC/VI did not have a recorded diagnosis of COPD or asthma; in these cases, it is possible that the patients' diagnosis had not been coded during the period of data availability resulting in misclassification of offlabel use.

The IRs of cardiovascular events were similar for UMEC and UMEC/VI users. Other studies using the THIN and CPRD GOLD databases have reported higher IRs of cardiovascular events in new users of LAMA, LABA, or LAMA/ LABA. ${ }^{16,17}$ Reported incidence of MI range between 10 and 13 per 1000 person-years compared with 6.8-6.9 per 1000 person-years in this study, and reported incidences of CHF range between 29 and 46 per 1000 person-years compared with 11-14.8 per 1000 person-years in our study. ${ }^{16,17}$ The higher incidence reported in the previous studies may be explained by a number of factors: both earlier studies were restricted to patients over 55 years of age at index date, whereas no age restriction was imposed in the current study; the earlier studies examined incidence between 2003 and 2013, compared with 2014-2016 in the current study; and there were differences in the codes and algorithms used to identify cases. Previous studies have also reported a lower IR of stroke (8-16 per 1000 person-years $)^{16,17}$ than in the current study (30.5-30.9 per 1000 person-years). The inclusion of codes for transient ischemic attack in the case 
identification algorithm may have contributed to the higher rates seen in the current study.

In the primary care cohort, rates of pneumonia and AECOPD were slightly higher among UMEC versus UMEC/VI users, which may have been due to UMEC patients having more severe COPD. Similarly, in both UMEC and UMEC/VI users, AECOPD tended to be higher among patients taking concomitant ICS at index date, who were also likely to have more severe disease. Compared with the primary care cohort, the linked cohort had higher IRs of pneumonia and AECOPD exacerbations for new users of UMEC and UMEC/VI; however, for the primary care cohort, moderate AECOPD were analyzed whereas the linked cohort included moderate and severe AECOPD. The HES data identified severe pneumonia cases resulting in hospital admission; less severe cases of pneumonia treated in primary care, often without x-ray confirmation, may have been recorded using non-specific codes such as lower respiratory tract infection, and therefore would not be counted as pneumonia in the primary care data. Previous studies using CPRD-HES linked data reported similar rates of pneumonia resulting in hospitalization among patients with COPD on LAMA/LABA (51 per 1000 patient-years) ${ }^{18}$ and LAMA (53 per 1000 patient-years) maintenance therapy. ${ }^{16}$ Another study using CPRD GOLD-HES linked data reported higher rates of pneumonia (107 per 1000 patient-years); ${ }^{19}$ however, that study population consisted of users of all inhaled maintenance therapy (including ICS, LAMA, LAMA/LABA, and ICS/LAMA/LABA) and the inclusion of ICS-exposed patients likely accounted for the higher rate. Likewise, moderate or severe AECOPD rates in the same study using CPRD-HES linked data were similar to those observed in our study; for LAMA/LABA without ICS use they found an IR of 907 per 1000 patient-years $^{18}$ versus 1029 per 1000 patient-years in our study.

Mortality rates reported in this study for the linked cohort were similar to those reported in a previous study using the same dataset for other maintenance therapies (aclidinium 32.9 per 1000 patient-years; tiotropium 45.1 per 1000 patient years; other LAMAs 39.3 per 1000 patient-years and other LABAs 39.9 per 1000 patientyears). ${ }^{20}$ Mortality rates were lower in the on-treatment analysis compared with the analysis of all follow-up time, suggesting that mortality increased after patients discontinued their medication. However, it may also be in part due to the additional follow-up time occurring later in the course of a progressive disease, or because some patients may have switched to UMEC or UMEC/VI due to disease deterioration and this treatment may have been discontinued if their condition continued to deteriorate.

Treatment patterns in the 12 months after initiating treatment suggest that UMEC and UMEC/VI were well tolerated by most patients, with approximately one-third of UMEC and UMEC/VI users switching or permanently discontinuing their index medication during this time. The adherence of the index treatment was higher among those who received concomitant COPD maintenance therapy than among those who received only UMEC or only UMEC/VI. Thus, $67.5 \%$ versus $35.4 \%$ continued with UMEC for $\geq 12$ months and $49.4 \%$ versus $44.3 \%$ continued with UMEC/VI for $\geq 12$ months. This might indicate a better adherence to an open triple therapy specially among UMEC users.

Medication adherence in COPD is an important issue for patients and health care systems. Non-adherence to COPD maintenance treatment is common and is associated with significant negative impact on morbidity, healthcare costs, quality of life, and mortality. ${ }^{21,22}$ Adherence estimated for new users of UMEC/VI from PDC $\geq 80 \%$ in this study $(33 \%)$ was comparable to adherence reported in previous studies using the same measure (approximately $29 \%)^{23,24}$ When assessing adherence, it is important to note that neither MPR or PDC can account for primary non-adherence because it is not possible to identify prescriptions that were issued but not dispensed.

Several limitations should be considered in the interpretation of the findings of this study. This study included UK data and as such may not be generalizable to other countries. There are some inherent issues with using EHR data. Diagnoses were recorded using data coded by GPs in EHRs, which may have resulted in inaccurate identification of patients without a diagnosis for COPD or asthma because their medical record did not contain a coded diagnosis. There is also the potential to misdiagnose COPD as asthma, or vice versa, particularly in patients over 40 years of age, ${ }^{25}$ and some patients may have both conditions. New exposure to UMEC/VI, UMEC, or other LABD was based on records of GPprescribed medications; prescriptions initiated in hospitals or secondary care were not accessible for analysis. This may have led to an underestimation of UMEC and UMEC/VI prescribing, off-label use and adherence. Moreover, prescribed medications might not have been dispensed at the pharmacy or utilized by the patient. As such, this study is only able to assess off-label prescribing 
and cannot make strong inferences about off-label use. Finally, although LAMA and LAMA/LABA are still part of the treatment guidelines for patients with COPD, and our study findings can be applicable to the current practice, there has been some shift in treatment over the last few years towards the use of MITT or single-inhaled triple therapy that should be considered.

A strength of this study was that patients from two primary care databases were combined to facilitate faster accrual of data on the newly approved treatments and to give a more representative sample. Furthermore, linking the primary care data with HES and ONS data allowed more complete assessment of safety outcomes, including deaths.

\section{Conclusions}

This study of the use of UMEC and UMEC/VI in clinical practice in the UK provides evidence that these COPD maintenance therapies are being prescribed according to their labels and respiratory guidelines. In most cases, UMEC was prescribed as step-up therapy to MITT. The incidence of the cardiovascular, respiratory, and mortality events was consistent with that reported in other studies.

\section{Abbreviations}

AECOPD, acute exacerbations of COPD; BMI, body mass index; CHF, congestive heart failure; $\mathrm{CI}$, confidence interval; CPRD, Clinical Practice Research Datalink; COPD, chronic obstructive pulmonary disease; EHR, electronic health record; ENCePP, European Network of Centres for Pharmacoepidemiology and Pharmacovigilance; $\mathrm{FEV}_{1}$, forced expiratory volume in 1 second; GP, general practitioner; GOLD, Global Initiative for Chronic Obstructive Lung Disease; HES, Hospital Episode Statistics; ICS, inhaled corticosteroid; IR, incidence rate; ISAC, Independent Scientific Advisory Committee; LABA, longacting $\beta_{2}$-agonist; LABD, long-acting bronchodilator; LAMA, long-acting muscarinic antagonist; MHRA, Medicines and Healthcare products Regulatory Agency; MI, myocardial infarction; MITT, multiple-inhaler triple therapy; MPR, medication possession ratio; MRC, Medical Research Council; NHIR, National Institute for Health Research; NHS, National Health Service; ONS, Office of National Statistics; PDC, proportion of days covered; SD, standard deviation; SRC, Scientific Review Committee; THIN, The Health Improvement Network; UMEC, umeclidinium; VI, vilanterol.

\section{Data Sharing Statement}

CPRD data are available from the Clinical Practice Research Datalink. Anyone who would like to use CPRD data will need to first submit an application to the Independent Scientific Advisory Committee (ISAC) of the Medicines and Healthcare products Regulatory Agency (MHRA) http://www.cprd.com/ISAC/.

\section{Ethics Approval and Informed Consent}

The study used the CPRD and THIN databases of pseudonymized patient EHRs therefore patients' informed consent was not required. The study protocol was approved by GlaxoSmithKline's (GSK's) Protocol Review Committee on June 27, 2014, registered on the European Network of Centres for Pharmacoepidemiology and Pharmacovigilance (ENCePP), and received ENCePP seal of approval (ENCEPP/SDPP/7761). CPRD Independent Scientific Advisory Committee (ISAC) approval for this study was obtained in March 2017, ISAC protocol number 17_023. THIN Scientific Review Committee (SRC) approval for this study was obtained in March 2017, THIN protocol number 17THIN018.

\section{Acknowledgments}

The authors would like to acknowledge the contribution of Sonia J. Coton (Clinical Practice Research Datalink, MHRA, London, UK) who was involved in the conception/design of the study, acquisition of data and analysis/ interpretation of data. Medical writing support was provided by Alexandra Berry and Katie White, PhD, of Fishawack Indicia Ltd, UK, part of Fishawack Health, funded by GSK. CPRD is jointly sponsored by the UK government's Medicines and Healthcare products Regulatory Agency and the National Institute for Health Research (NIHR). As a not-for-profit UK government body, CPRD seeks to recoup the cost of delivering its research services to academic, industry, and government researchers through research user license fees.

\section{Author Contributions}

All authors made substantial contributions to conception and design, acquisition of data, or analysis and interpretation of data; took part in drafting the article or revising it critically for important intellectual content; agreed to submit to the current journal; gave final approval of the version to be published; and agree to be accountable for all aspects of the work. 


\section{Funding}

This study was funded by GSK (study number 117397). GSK-affiliated authors had a role in the study design, data analysis, data interpretation, and writing of the report.

\section{Disclosure}

GR is an employee of GSK and holds stocks/shares in GSK. DD, REG, and RW are employees of CPRD. JKQ has received funds from The Health Foundation, MRC, GSK, Bayer, Boehringer Ingelheim, British Lung Foundation (Asthma UK), IQVIA, Chiesi, AstraZeneca, Insmed, and Asthma UK, and grants and personal fees from GSK, Boehringer Ingelheim, AstraZeneca, Bayer, and Insmed. JMP was an employee of GSK at the time of the study and holds stocks/shares in GSK. The authors report no other conflicts of interest in this work.

\section{References}

1. Global Initiative for Chronic Obstructive Lung Disease. Global strategy for the diagnosis, management and prevention of chronic obstructive pulmonary disease 2021 report; 2021. Available from: https:// goldcopd.org/wp-content/uploads/2020/11/GOLD-REPORT-2021-v1. 1-25Nov20 WMV.pdf. Accessed March 05, 2021.

2. Global Initiative for Asthma. Asthma Management and Prevention for Adults and Children Older than 5 Years: A Pocket Guide for Health Professionals; 2020. Available from: https://ginasthma.org/wp-content/ uploads/2020/04/Main-pocket-guide_2020_04_03-final-wms.pdf. Accessed March 05, 2021.

3. National Institute for Health and Care Excellence. Asthma: tiotropium (Spiriva Respimat). 2015. Available from: https://www.nice.org.uk/ advice/esnm55/chapter/Key-points-from-the-evidence. Accessed March 05, 2021.

4. European Medicines Agency. Anoro Ellipta (umeclidinium bromide/ vilanterol) An overview of Anoro Ellipta and why it is authorised in the EU; 2018. Available from: https://www.ema.europa.eu/en/docu ments/overview/anoro-ellipta-epar-medicine-overview_en.pdf. Accessed 26 June, 2020.

5. European Medicines Agency. Incruse Ellipta (umeclidinium bromide) An overview of Incruse Ellipta and why it is authorised in the EU; 2018. Available from: https://www.ema.europa.eu/en/documents/over view/incruse-ellipta-epar-medicine-overview_en.pdf. Accessed 18 June, 2020.

6. Ray R, Tombs L, Naya I, Compton C, Lipson DA, Boucot I. Efficacy and safety of the dual bronchodilator combination umeclidinium/vilanterol in COPD by age and airflow limitation severity: a pooled post hoc analysis of seven clinical trials. Pulm Pharmacol Ther. 2019;57:101802. doi:10.1016/j.pupt.2019.101802

7. Maleki-Yazdi MR, Kaelin T, Richard N, Zvarich M, Church A. Efficacy and safety of umeclidinium/vilanterol $62.5 / 25 \mathrm{mcg}$ and tiotropium $18 \mathrm{mcg}$ in chronic obstructive pulmonary disease: results of a 24-week, randomized, controlled trial. Respir Med. 2014;108 (12):1752-1760. doi:10.1016/j.rmed.2014.10.002

8. Donohue JF, Maleki-Yazdi MR, Kilbride S, Mehta R, Kalberg C, Church A. Efficacy and safety of once-daily umeclidinium/vilanterol 62.5/25 mcg in COPD. Respir Med. 2013;107(10):1538-1546. doi:10.1016/j.rmed.2013.06.001
9. Zheng J, Zhong N, Newlands A, Church A, Goh AH. Efficacy and safety of once-daily inhaled umeclidinium/vilanterol in Asian patients with COPD: results from a randomized, placebo-controlled study. Int J Chron Obstruct Pulmon Dis. 2015;10:1753-1767. doi:10.2147/copd.s81053

10. Albertson TE, Bowman WS, Harper RW, Godbout RM, Murin S. $<\mathrm{p}>$ Evidence-based review of data on the combination inhaler umeclidinium/vilanterol in patients with COPD. Int $J$ Chron Obstruct Pulmon Dis. 2019;14:1251-1265. doi:10.2147/COPD.S191845

11. Pleasants RA, Wang $T$, Gao J, Tang $H$, Donohue JF. Inhaled Umeclidinium in COPD patients: a review and meta-analysis. Drugs. 2016;76(3):343-361. doi:10.1007/s40265-015-0532-5

12. Feldman G, Maltais F, Khindri S, et al. A randomized, blinded study to evaluate the efficacy and safety of umeclidinium $62.5 \mu \mathrm{g}$ compared with tiotropium $18 \mu \mathrm{g}$ in patients with COPD. Int J Chron Obstruct Pulmon Dis. 2016;11:719-730. doi:10.2147/COPD.S102494

13. Trivedi R, Richard N, Mehta R, Church A. Umeclidinium in patients with COPD: a randomised, placebo-controlled study. Eur Respir J. 2014;43(1):72-81. doi:10.1183/09031936.00033213

14. Rothnie KJ, Müllerová H, Hurst JR, et al. Validation of the Recording of Acute Exacerbations of COPD in UK Primary care electronic healthcare records. PLoS One. 2016;11(3):e0151357. doi:10.1371/ journal.pone. 0151357

15. Rothnie KJ, Müllerová H, Thomas SL, et al. Recording of hospitalizations for acute exacerbations of COPD in UK electronic health care records. Clin Epidemiol. 2016;8:771-782. doi:10.2147/CLEP. S117867

16. Suissa S, Dell'Aniello S, Ernst P. Long-Acting Bronchodilator Initiation in COPD and the risk of adverse cardiopulmonary events: a population-based comparative safety study. Chest. 2017;151 (1):60-67. doi:10.1016/j.chest.2016.08.001

17. Jara M, Wentworth C, Lanes S. A new user cohort study comparing the safety of long-acting inhaled bronchodilators in COPD. BMJ Open. 2012;2(3):e000841. doi:10.1136/bmjopen-2012-000841

18. Suissa S, Dell'Aniello S, Ernst P. Comparative Effectiveness and Safety of LABA-LAMA vs LABA-ICS Treatment of COPD in RealWorld Clinical Practice. Chest. 2019;155(6):1158-1165. doi:10.1016/ j.chest.2019.03.005

19. Pate A, Barrowman M, Webb D, et al. Study investigating the generalisability of a COPD trial based in primary care (Salford Lung Study) and the presence of a Hawthorne effect. BMJ Open Respir Res. 2018;5(1):e000339. doi:10.1136/bmjresp-2018-000339

20. Rebordosa C, Aguado J, Plana E, et al. Use of aclidinium did not increase the risk of death in a noninterventional cohort study in the Clinical Practice Research Datalink (CPRD), United Kingdom. Respir Med. 2019;152:37-43. doi:10.1016/j.rmed.2019.04.018

21. Bourbeau J, Bartlett SJ. Patient adherence in COPD. Thorax. 2008;63 (9):831-838. doi:10.1136/thx.2007.086041

22. Mäkelä MJ, Backer V, Hedegaard M, Larsson K. Adherence to inhaled therapies, health outcomes and costs in patients with asthma and COPD. Respir Med. 2013;107(10):1481-1490. doi:10.1016/j. rmed.2013.04.005

23. Moretz C, Bengtson LG, Sharpsten L, et al. $<\mathrm{p}>$ Evaluation of rescue medication use and medication adherence receiving umeclidinium/ vilanterol versus tiotropium bromide/olodaterol. Int J Chron Obstruct Pulmon Dis. 2019;14:2047-2060. doi:10.2147/COPD.S213520

24. Moretz C, Sharpsten L, Bengtson LG, et al. $<\mathrm{p}>$ Real-world effectiveness of umeclidinium/vilanterol versus fluticasone propionate/salmeterol as initial maintenance therapy for chronic obstructive pulmonary disease (COPD): a retrospective cohort study. Int $J$ Chron Obstruct Pulmon Dis. 2019;14:1721-1737. doi:10.2147/COPD.S204649

25. Tinkelman DG, Price DB, Nordyke RJ, Halbert RJ. Misdiagnosis of COPD and asthma in primary care patients 40 years of age and over. J Asthma. 2006;43(1):75-80. doi:10.1080/02770900500448738 


\section{Publish your work in this journal}

The International Journal of COPD is an international, peer-reviewed journal of therapeutics and pharmacology focusing on concise rapid reporting of clinical studies and reviews in COPD. Special focus is given to the pathophysiological processes underlying the disease, intervention programs, patient focused education, and self management protocols. This journal is indexed on PubMed Central, MedLine and CAS. The manuscript management system is completely online and includes a very quick and fair peer-review system, which is all easy to use. Visit http://www.dovepress.com/testimonials.php to read real quotes from published authors. 